Die Symptome, die auf einen Hypophysistumor hindeuteten, waren: anfallweise Kopfschmerzen, Flimmern und Abnahme der Sehkraft zuerst auf dem linken, dann noch mehr auf dem rechten Auge (temporale Hemianopsie, Optikusatrophie), zuletzt rechts fast völlige Blindheit, Zerstörung der vorderen und hinteren Begrenzung der Sella turcica durch die Röntgenuntersuchung festgestellt. Leichter Exophthalmus rechts. Bedeutende Polyurie. Die zum Zwecke der Herabsetzung des Firndruckes vorgenommene Operation geschah nach der endonasalen Methode von Hirsch. Als die Keilbeinhöhle eröffnet war, zeigten sich das ganze Dach, sowie die hintere Wand zerstört, und es wölbten sich die stark geröteten, nachgiebigen und lebhaft pulsierenden Weichteile in die Höhle hinein. Fs wurde ein Löffel in der Mittellinie durch die Dura mater in die Hypophysis eingeführt, mit Entleerung von etwas breiiger Tumormasse und ziemlich reichlichem AusfluB blutgefärbter Flüssigkeit. Finige Tage nach der Operation meningeale. Reizsymptome mit hohem Fieber und noch weitere Abnahme der Sebkraft, offenbar vèrursacht durch eine Sekretverhaltung in der Wundhöhle, die sich durch Einführung eines schmalen Tampons in diese verhïten ließe. Schließlicher Erfolg: Kopfschmerzen verschwundan, Sehschärfe links auf $2 / 10$ gebessert. Blau.

\title{
Die Preise des Internationalen medizinischen Kongresses.
}

Gelegentlich des XVII. Internationalen medizinischen Kongresses in London sollen folgende Preise zur Vertellung gelangen: 1. der Preis der Stadt Moskau, 5000 Fr., für die beste Arbeit auf dem Gebiete der Medizin oder Hygiene oder für hervorragende, der leidenden Menschheit geleistete Dienste; 2. der Preis des XIII. Internationalen medizinischen Kongresses zu Paris, 4000 Fr., an eine einzelne Person verleihbax, und zwar für eine Entdeckung oder eine Gesamtheit von Arbeiten, die nicht älter als 10 Jahre sind und dem Gebiet der inneren Medizin, Chirurgie, Geburtshilfe oder der anatomischen oder biologischen Wissenschaften in ihrer Beziehung zur Medizin angehören; 3. der Preis von Ungarn, $3000 \mathrm{Kr}$., für eine Arbeit aus dem Gebiet der medizinischen Wissenschaften, die zwischen dem diesjährigen und dem letzten Internationalen KongreB erschienen ist.

Die Herren Kollegen werden gebeten, die Namen der für eine Preiserteilung Geeigneten zu nennen. Eixe Selbstkandidatur ist gestattet.

Bewerbungen sind unter Einreichung eines Exemplares des Werkes, auf welches der Anspruch sich stützt, bis spätestens zum 1. Juni an das Bureau der permanenten Kommission der Internationalen medizinischen Kongresse, Der Haag (Niederlande), Hugo de Grootstraat $10 \mathrm{zu}$ richten. Die Preiserteilung findet während dés Londoner Kongresses im August 1913 statt. 